\title{
BODY OF KNOWLEDGE FOR THE EARTH OBSERVATION AND GEOINFORMATION SECTOR - A BASIS FOR INNOVATIVE SKILLS DEVELOPMENT
}

\author{
M. A. Stelmaszczuk-Górska ${ }^{1, *}$, E. Aguilar-Moreno², S. Casteleyn², D. Vandenbroucke ${ }^{3}$, M. Miguel-Lago ${ }^{4}$, C. Dubois ${ }^{1}$, \\ R. Lemmens ${ }^{5}$, G. Vancauwenberghe ${ }^{3}$, M. Olijslagers ${ }^{3}$, S. Lang ${ }^{6}$, F. Albrecht ${ }^{6}$, M. Belgiu ${ }^{5}$, V. Krieger ${ }^{7}$, T. Jagdhuber ${ }^{8}$, A., Fluhrer $^{8}$, \\ M. J. Soja ${ }^{9}$, A. Mouratidis ${ }^{10}$, H. J. Persson ${ }^{11}$, R. Colombo ${ }^{12}$, G. Masiello ${ }^{13}$
${ }^{1}$ Dept. for Earth Observation, Friedrich-Schiller University of Jena, Germany - (clemence.dubois, m.stelmas)@uni-jena.de
${ }^{2}$ Institute of New Imaging Technologies, University Jaume I of Castellon, Spain - (eaguilar, sven.casteleyn)@uji.es
${ }^{3}$ Spatial Applications Division Leuven, KU Leuven, Belgium (marc.olijslagers, glenn.vancauwenberghe, danny.vandenbroucke)@kuleuven.be
${ }^{4}$ European Association of Remote Sensing Companies, Belgium - monica.miguel-lago@earsc.org
${ }^{5}$ Faculty of Geo-Information Science and Earth Observation, University of Twente, The Netherlands (m.belgiu, r.l.g.lemmens)@utwente.nl ${ }^{7}$ Spatial Services GmbH, Austria - veronika.krieger@spatial-services.com
${ }^{8}$ Microwaves and Radar Institute, German Aerospace Center (DLR), Germany - (Anke.Fluhrer, Thomas.Jagdhuber)@dlr.de
${ }^{9}$ MJ Soja Consulting, Australia and University of Tasmania, Australia - maciej@mjsoja.com
${ }^{11}$ Swedish University of Agricultural Sciences (SLU), Sweden - henrik.persson@slu.se
${ }^{13}$ School of Engineering, University of Basilicata, Italy - (guido.masiello)@unibas.it \\ ${ }^{6}$ Interfaculty Department of Geoinformatics - Z_GIS, University of Salzburg, Austria - (florian.albrecht, stefan.lang)@sbg.ac.at \\ ${ }^{10}$ Department of Physical and Environmental Geography, Aristotle University of Thessaloniki, Greece - amourati@geo.auth.gr \\ 12 University of Milano - Bicocca, Department of Earth and Environmental Sciences, Milan, Italy - roberto.colombo@unimib.it
}

\section{Commission V, WG V/1}

KEY WORDS: Body of Knowledge, Earth Observation, Geoinformation, Skills definition, Market/User Uptake

\begin{abstract}
:
With new Earth Observation (EO) and Geoinformation (GI) data sources increasingly becoming available, evermore new skills for data collection, processing, analysis and application are required. They are needed not only from scientists, but also from practitioners working in businesses, public and private EO*GI and related sectors. Aligning the continuously evolving skill sets demanded by the market and existing academic and vocational training programmes is not an easy task. Training programmes should be grounded in real needs of the sector and its labour market. To do this, it is necessary to identify the knowledge and skills needed, and map their interconnectivity in specific frameworks, which can later be used for the definition of new curricula or job-oriented learning paths. This paper presents a framework for the EO*GI sector, based on a Body of Knowledge (BoK), by creating a complete set of concepts with a semantic structure underneath that supports academia and industry. Creating and updating the BoK is supported by an editing tool, the Living Textbook and by experts in the EO*GI domain, who contributes to the BoK's enrichment.
\end{abstract}

\section{INTRODUCTION}

The Earth Observation and Geographic Information/ Geoinformation sector (EO*GI) is a rapidly developing field. Technological changes driven by big EO data collection and analysis (Sudmanns et al., 2019) induce a paradigm shift in learning and knowledge transfer, which needs to be considered for the creation of future EO*GI curricula and training actions. The project 'Towards an innovative strategy for skills development and capacity building in the space geoinformation sector supporting Copernicus user uptake' (EO4GEO) is an Erasmus+ Sector Skills Alliance which aims to respond to the current and upcoming challenges in EO*GI education. EO4GEO brings together experts from academia and the public and private sectors to define and apply innovative solutions for education and training actions, based on a Body of Knowledge (BoK). In this paper, we present the main characteristics of the BoK and its pivotal function as a reference for tools for education and training activities in the $\mathrm{EO}^{*} \mathrm{GI}$ sector.

After providing a definition of the BoK, its importance for the EO*GI domain is highlighted (Section 2). Then, the historical perspective is given (Section 3). The main part of this paper focuses on the BoK implementation for the $\mathrm{EO} * \mathrm{GI}$ sector (Section 4). The structure, identification of relevant knowledge and skills, current content and the BoK maintenance mechanisms and examples of applications are outlined. Finally, Section 5 provides an overview of the main users.

\section{BODY OF KNOWLEDGE}

\subsection{Definition}

A Body of Knowledge (BoK) is a formal description of a domain represented by a complete set of concepts in a structured way, including the theories, methods and technologies that can be used by members of a discipline to guide their education and work practice (DiBiase et al., 2006). The BoK represents a combination of knowledge, skills and competencies required to master a particular area or profession (or rather several professions), and hence it should be widely accepted by academia as well as the private and public sectors. This can be done for example by agreeing on a common vocabulary in order to better understand and communicate with each other. Many domains and sectors already have their BoK. For example, PMBOK is a BoK

\footnotetext{
* Corresponding author
} 
related to Project Management (PMI, 2017), while the DAMA DMBOK is a BoK describing the field of Data Management (DAMA International, 2017).

\subsection{Importance of a BoK for a sector}

The BoK defines what knowledge is needed to complete a job or task in a specific domain, and thus contributes to professional development needs. There is a long list of reasons that make a BoK a relevant reference guide for a sector (Fairbairn, 2017). Amongst others:

- It is a formal and updated set of basic knowledge, skills and competences required.

- It forms a foundation for developing the curriculum for most professional programs and vocational training, including accreditations at different qualification levels.

- It supports workforce recruitment and job assessments.

- It is especially useful for career planning, for people seeking to enter, change or improve qualifications (Dupuis et al., 2003). As shown in studies in the context of European projects (Cipriano et al., 2013; Rip et al., 2014; Hofer et al., 2019), or by European associations and the European Commission in the framework of Space market uptake in Europe (Delponte et al., 2016) and Copernicus market analysis (PwC, 2019), the space/geospatial sector requires a skills strategy. This strategy should bridge the reported gaps and mismatches between the supply of and demand for education and training in the sector (Mouratidis, Koutsoukos, 2016) and is expected to foster the Space/Copernicus user uptake. In order to keep up with the rapid developments in the Earth Observation and Geoinformation sector and to bridge the skills gap between supply and demand of education and training in the space/geospatial sector a skills strategy was proposed (MiguelLago et al., 2019). The BoK for EO*GI is an important tool that will support this strategic blueprint. The collected concepts are translated into skills demanded by the EO*GI sector as well as into learning objectives addressed by education and training initiatives. Therefore, it facilitates a way for establishing a link between the supply of and demand for EO*GI skills.

\section{STATE-OF-THE-ART - BODY OF KNOWLEDGE FOR EARTH OBSERVATION AND GEOINFORMATION}

The first attempt to comprehensively describe the geospatial domain in the form of a set of concepts describing the basic theory, technical and applications topics was taken by the United States National Center for Geoinformation and Analysis (NCGIA) in order to develop the core curriculum required in the new discipline at that time, i.e. in the 1980s, the Geographic Information Systems (GIS) (Kemp, Goodchild, 1991). The description of the geospatial domain in the form of a BoK was taken by the University Consortium for Geographic Information Science (UCGIS), and it resulted in the Geographic Information Science and Technology (GIS\&T) BoK published as a book in 2006 (DiBiase et al., 2006). The GIS\&T BoK represented a set of concepts grouped in ten knowledge areas: 'Analytical Methods', 'Conceptual Foundations', 'Cartography and Visualization', 'Design aspects', 'Data Modeling', 'Data manipulation', 'Geocomputation', 'Geospatial Data', 'GIS\&T Society', and 'Organizational and Institutional Aspects'.

Since then, two approaches of the GIS\&T BoK have been pursued - one in the United States and one in Europe.

An academic approach is favoured in the United States where more than three hundred concepts (topics) are hierarchically structured and described in the form of scientific, peer-reviewed documents (Wilson, 2020). The original GIS\&T BoK concepts have been reviewed and updated according to recent developments in the sector. Obsolete topics have been removed, while new knowledge has been added in areas such as 'Programming and Development', 'Computing Platforms', 'Knowledge Economy' and 'Domain Applications'. Each topic is uniquely identified using a DOI and a permanent URL.

Based on a semantic web technology solution developed by Ahearn et al. (2013) for the GIS\&T BoK, the first European version of the BoK was developed as a part of the Geographic Information Need to Know (GI-N2K ${ }^{1}$ ) project (Vandenbroucke, Vancauwenberghe, 2016). The GI-N2K BoK resulted in the appearance of a new knowledge area (KA) 'Web based GI', the re-organisation of 'Data Modeling', the reformulation of whole KAs (e.g., 'Design and set up of Geographic information systems'), and the inclusion, deletion or update of concepts in different KAs. The GI-N2K BoK had 436 concepts, which were interconnected based on five relationship types: super-concept, sub-concept (allowing to generate the existing hierarchies already expressed in the first version of the GIS\&T BoK), preand post-requisites (representing a learning sequence), and similarity (a non-hierarchical relationship).

Neither the American nor the European GIS\&T and GI-N2K BoKs include comprehensive information on EO.

\section{IMPLEMENTATION OF THE EO4GEO BOK}

\subsection{Structure of the BoK}

The BoK for EO*GI, which is developed as part of the EO4GEO project, builds on a revision of the GI-N2K BoK (Vandenbroucke et al., 2019). To ease the BoK implementation, in the first phase of the BoK development, the GI concepts were grouped thematically in three working groups (WGs). Additionally, four EO WGs were specified, focusing on EO principles and applications. As a result, the BoK extension has been organized in seven interconnected WGs: 'WG1 Analytical Methods and GI Foundations', 'WG2 Visualization and GI Systems', 'WG3 Spatial Data Infrastructures and Related Concepts', 'WG4 Physical Principles of Remote Sensing', 'WG5 Platforms, Sensors and Digital Imagery', 'WG6 Image Processing and Analysis', 'WG7 Thematic and Application Domains'. After establishing the groups, the BoK started to be filled up with new and updated content.

Work in the first three groups (GI) began with a review of existing concepts inherited from the GI-N2K BoK and identification of new concepts. Meanwhile, work in the other groups (EO) started with the formulation of core concepts, as only 14 concepts directly related to remote sensing were found in the GI-N2K BoK. The EO and GI concepts will make up the EO4GEO BoK.

\subsection{Development of the EO4GEO BoK}

The EO4GEO BoK development focuses on three main aspects, which refine the two different approaches followed in the United States and Europe. First, it aims at extending the BoK with EOrelated concepts and updating the existing GI concepts. Second, it is strongly focused on the creation of an ontology for the EO*GI domain. Third, it aims at adding a business-oriented perspective (Hofer et al. 2020b), as the previous version of the BoK was mainly developed for the academic sector (Rickles et al., 2017).

A simplified workflow (Figure 1) covers the expert-based BoK development which addresses points 1 and 2 , and it is

${ }^{1}$ www.gi-n2k.eu 
complemented with an analytical part, which corresponds with the business perspective (point 3).

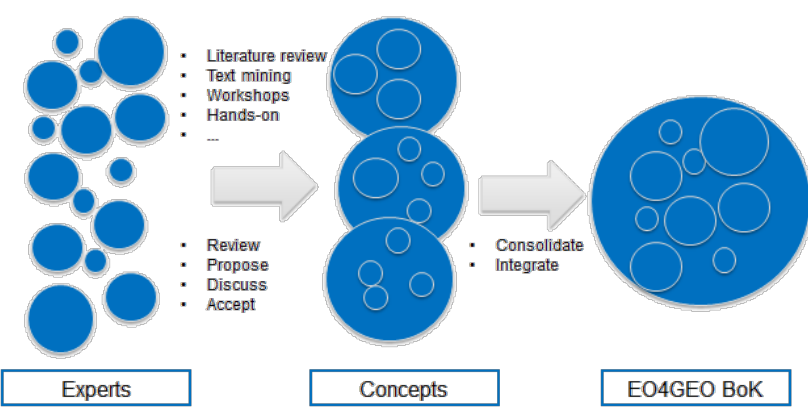

Figure 1. Workflow of the EO4GEO BoK development and its main elements: experts and concepts

Concepts, i.e., the description of knowledge and skills required to master the $\mathrm{EO} * \mathrm{GI}$ domain, constitute the main content of the BoK. They are developed based on the work of experts, who are scientists and practitioners from the EO*GI industry. To ensure the BoK consistency and common vocabulary used by different stakeholders in the EO*GI sector, guidelines have been defined for describing the identified knowledge and skills. Experts review, propose and discuss concepts. Once the concept is accepted by a group of experts, it is integrated into the ontological structure that shapes the EO4GEO BoK.

Considering this overarching workflow and the three main objectives, the BoK development process will be presented in detail in the next sections. First, the main elements of the concept, i.e. knowledge and skills, will be described, followed by the relations between them.

4.2.1 Knowledge - Identification of EO-related and revision of GI concepts: 'Knowledge means the outcome of the assimilation of information through learning. Knowledge is the body of facts, principles, theories and practices that is related to a field of work or study.' (EU, 2017).

To review and identify new knowledge in the form of concepts, different methods were used in different WGs. Some of the concepts inherited from the GI-N2K BoK were incomplete, for this reason, the focus was on improving their descriptions (WG2). In other cases, concepts needed harmonisation (WG1) or the main task was the identification of missing concepts (WG3). Due to the limited number of concepts in the GI-N2K BoK directly related to remote sensing, EO groups (WG4-WG7) focused on identifying and defining the concepts, considering the new trends and developments of the industry. The four established EO groups of concepts focus on the physical properties of optical and microwave remote sensing (WG4), remote sensing sensors and platforms, as well as the properties of digital imagery (WG5), image processing and analysis, grouped into four concepts: image pre-processing, data assimilation, image understanding, and data infrastructure (WG6), as well as the knowledge and skills related to applications, grouped into three main concepts: EO for societal and environmental challenges, EO thematic areas and user community of EO services and applications (WG7).

Core concepts, new trends and technological advances in the sector were identified based on reviews of scientific literature, including scientific papers, books, and key documents and initiatives of leading bodies and organizations in the domain of GI and EO. Examples include the technology trends watch of the
Open Geospatial Consortium (OGC), United Nations initiative on Global Geospatial Information Management (UN-GGIM), the Joint Research Centre (JRC) managing the INSPIRE Tasks Vocabularies, European Space Agency (ESA), National Aeronautics and Space Administration (NASA), the Committee on Earth Observation Satellites (CEOS) and its Working Groups. The review of the scientific literature was based on a set of searches performed in scientific databases such as Scopus and Web of Science. Several search alerts were created, combining terms like 'trends, challenges, review, agenda or advances' with concepts at upper levels (GI, GIS, SDI, Cartography, Visualization, etc.) and deeper levels as well. The amount of papers retrieved was very high $(>2,000)$. For this reason, additional tools were used to identify potential concepts. The bibliometric networks were constructed and visualized using the VOSViewer software ${ }^{2}$. The process allowed the extraction of key terms from the retrieved body of scientific literature, in order to i) detect co-occurrences and relations between concepts and ii) identify networks, including clusters of concepts.

Furthermore, user workshops at international conferences contributed to the definition and shaping of new concepts and their relations, e.g., the workshop at the ESA Living Planet Symposium in 2019.

As a result of the first round of the BoK extension (until June 2019), more than 1300 concepts were identified. Currently, the concepts are being reviewed and described by the experts. As of the end of April 2020 and after the first revision, the number of pre-identified concepts was reduced to 957, with the following distribution among the WGs: WG1: 124, WG2: 98, WG3: 175, WG4: 170, WG5: 134, WG6: 175, and WG7: 81 (Figure 2).
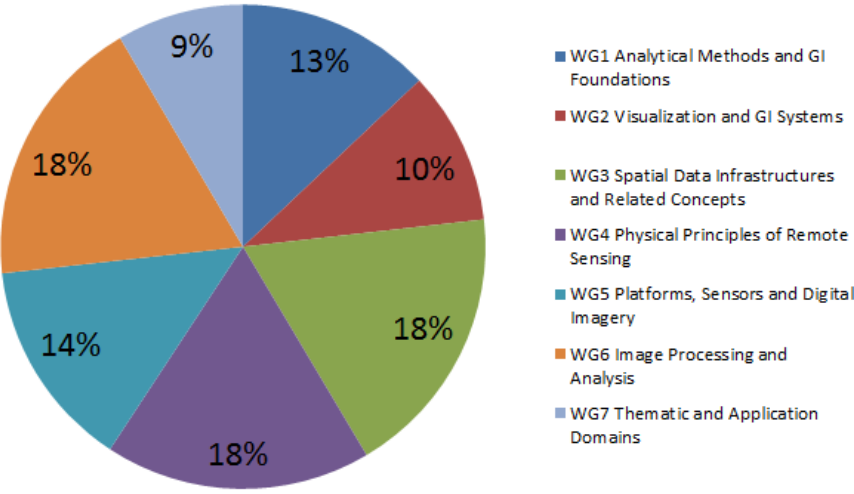

Figure 2. Current distribution of knowledge between the working groups making up EO4GEO BoK

The description of the 'knowledge' represented by a concept is formulated in the form of an abstract (approx. 250-500 words), describing the concept in a way accessible to a wider, non-expert audience and avoiding specialized terminology (jargon).

Each concept has at least one reference, following the American Psychological Association (APA) style. Any type of reference (e.g., research paper, book, report, weblink) is allowed as long as it is relevant for the concept and accepted by a wide range of experts.

4.2.2 Skills - Adding a business-oriented perspective to the EO4GEO BoK: 'Skills means the ability to apply knowledge and use know-how to complete tasks and solve problems.' (EU, 2017).

To add a business perspective to the EO4GEO BoK, an analysis on business processes was conducted, broken down into tasks

${ }^{2}$ www.vosviewer.com 
performed by the workforce of the EO*GI sector. It was done using the Business Process Modeling and Notation (BPMN) method, which outlines the workflow of the process and the actors involved (Rosing et al., 2015). In total, 30 example business processes were analyzed, identifying over 200 tasks (Vlad Sandru et al., 2020). These provided the basis for identifying not only new relevant knowledge, but also job profiles that are associated with job descriptions and indicate which academic programs and vocational training should be developed. The process of analysing the BPMNs and enriching the BoK with a business-oriented perspective has been described in detail by Hofer et al. (Hofer et al., 2020b), and is schematically summarized in Figure 3. It shows that the business process tasks 'grow' from the knowledge and skills, and thus feed back into the BoK and fill its gaps.

Additionally, to get the full picture of the market needs, the business-oriented perspective was completed by considering new job offers appearing in the EO*GI sector. The analysis of 119 recent job advertisements showed that the EO*GI sector looks for a workforce not only with up-to-date occupational skills, and especially skills related to data analysis and programming and development, but it also requires transversal or soft skills, such as 'project management' 'team work' or 'communication'. The combination of occupational and transversal skills is crucial (Gruijthuijsen et al. 2019).

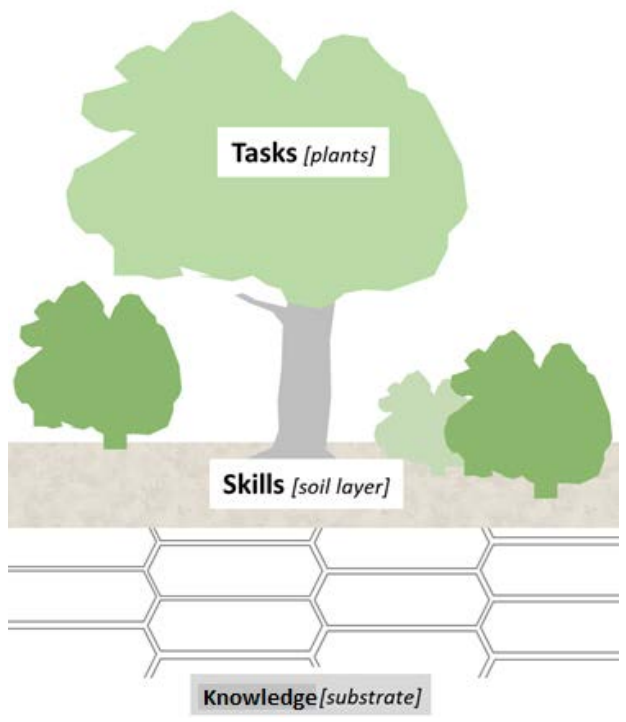

Figure 3. Completing the EO4GEO BoK with business-oriented knowledge and skills (Source: Hofer et al. 2020b, modified)

After an analysis of the tasks extracted from the BPMNs and their comparison with the existing skills present in the GI-N2K BoK, it was found that skills are a fundamental part of a concept. As it was conceived in the EO4GEO project, a skill could be interpreted as 'learning outcomes' for academia, or as a 'skill' competence or ability to perform a task - for industry. Therefore, skills are the thread that connect market and academia, so they have to be carefully considered. Consequently, the formulation of each skill should be composed of a verb (selected from a predefined list of verbs; Figure 4) and a concept-relevant statement (based on the title of a BoK concept). For that purpose, the EO4GEO partners have revised (Hofer et al., 2020b) the taxonomy of educational objectives prepared by Anderson and Krathwohl (2001) and based on Bloom et al. (1956), and created their own version by the addition of new verbs which are particularly relevant for the $\mathrm{EO} * \mathrm{GI}$ field. Skills in the resulting taxonomy are grouped in six levels, from the more general lower level skills (remember and understand) to the more specific higher-level skills (apply, analyze, evaluate and create).

\begin{tabular}{|c|c|c|c|c|c|}
\hline $\begin{array}{c}1 \\
\text { remember }\end{array}$ & $\begin{array}{c}2 \\
\text { understand }\end{array}$ & $\begin{array}{c}3 \\
\text { apply }\end{array}$ & $\begin{array}{c}4 \\
\text { analyze }\end{array}$ & $\begin{array}{c}5 \\
\text { evaluate }\end{array}$ & $\begin{array}{c}6 \\
\text { create }\end{array}$ \\
\hline choose & cite & apply & analyse & assess & add to \\
\hline define & classify & build & arrange & check & build \\
\hline find & compare & calculate & choose & choose & change \\
\hline identify & contrast & choose & classify & compare & choose \\
\hline list & deliver & classify & compare & decide & combine \\
\hline locate & demonstrate & construct & differentiate & defend & compile \\
\hline name & discuss & correlate & distinguish & determine & construct \\
\hline recognize & estimate & demonstrate & examine & estimate & convert \\
\hline relate & explain & develop & find & evaluate & create \\
\hline remember & illustrate & identify & install & explain & design \\
\hline select & indicate & illustrate & list & interpret & develop \\
\hline state & interpret & implement & order & judge & devise \\
\hline \multirow[t]{13}{*}{ write } & outline & interpret & prioritize & justify & discuss \\
\hline & relate & model & query & measure & estimate \\
\hline & report & organise & research & prioritize & manage \\
\hline & review & perform & select & recommend & model \\
\hline & understand & plan & & select & modify \\
\hline & & relate & & test & plan \\
\hline & & represent & & validate & process \\
\hline & & select & & & produce \\
\hline & & solve & & & propose \\
\hline & & teach & & & revise \\
\hline & & use & & & solve \\
\hline & & & & & test \\
\hline & & & & & transform \\
\hline
\end{tabular}

Figure 4. The list of verbs used to formulate skills in the EO4GEO BoK (Source: Hofer et al. 2020b)

4.2.3 Ontology - Creating the interconnections in the EO*GI sector: The BoK concepts are interrelated using relations that build the structure of the ontology. This functionality is supported by the Living Textbook (LTB) environment (Lemmens et.al, 2018). The LTB is a web-based tool developed by the University of Twente for modelling and visualising domain knowledge, which is currently used in education and starting to be deployed in projects for the purpose of knowledge sharing. It can be configured in a way that users can edit a conceptual framework collaboratively and identify gaps and overlaps in the model. Its interface combines a concept map with a text-based window containing the description of each concept, including its definition, required skills, external resources, contributors, etc. In the case of EO4GEO, these fields are currently being adapted as they still stem from the use of LTB in a pure educational setting. The LTB allows viewing, commenting and modifying the content of the BoK.

The borders between different WGs are not fixed. The knowledge areas link to each other by creating relations between concepts in the different WGs. Although more types of relations can be defined if necessary, at this stage of the BoK development the following relationship types are in place:

- Sub-concept (a concept on a lower granularity level)

- Prerequisite (one concept needs to be known to understand the other)

- $\quad$ Similarity (one concept is similar to another)

The sub-concept relation provides a way to build a traditional hierarchical structure in the BoK, and it implicitly implements the super-concept relation in the opposite direction. The main difference from the traditional tree structure is that a concept can be a sub-concept of more than one other concept, creating a richer 
ontology, in which inferences can be made across subdomains of knowledge (Figure 5).

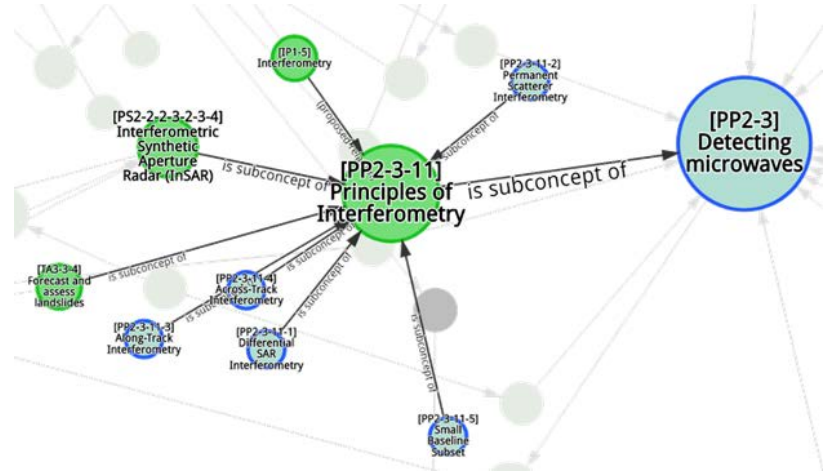

Figure 5. An example of sub-concept relation between concepts from different working groups (WG) marked in green; Principles of Interferometry super-concept for the concept 'Interferometry' in the 'WG6 Image Processing and Analysis', 'Interferometric Synthetic Aperture Radar (InSAR)' in the 'WG5 Platforms, Sensors and Digital Imagery' and 'Forecast and assess landslides' in the 'WG7 Thematic and Application Domains'

The prerequisite relation describes knowledge and skills that a person must possess before learning a certain concept, i.e. A 'is a prerequisite of' $\mathrm{B}$ means one cannot fully understand concept $\mathrm{B}$ if the knowledge about concept $\mathrm{A}$ is missing.

Similarity indicates a close resemblance between concepts. No excessive amount of similarity relations is expected inside the EO4GEO BoK. It will be mainly used to link to similar concepts in other, external databases that are frequently updated, e.g., ESA eoPortal Directory ${ }^{3}$ and CEOS Database ${ }^{4}$ to link to the past, current and planned EO missions and sensors, EARSC EO WIKI $^{5}$ to link to past and current application examples, and BoKs that complements the EO4GEO BoK, such as UCGIS GIS\&T Body of Knowledge, GEOINT Essential BoK (Brooks et al., 2019), ICA BoK (Moellering, 2019), Surveying BoK (Greenfeld, 2012) or Data Management BoK (DAMA DMBOK, 2017). At the moment, only the links to the sensor and mission databases as well as UCGIS GIS\&T BoK are established.

Other relationship types may be expected to be used later on, both for internal connections and to create links to external databases. Examples are 'is based on' and 'is used by'. Tentative relations are currently modelled in a generic manner, by using the 'is related to' relationship type.

\subsection{EO4GEO network of experts}

To serve its purpose, the BoK needs to be updated regularly and must represent both the academic and business-perspective in the field. To keep up with the new techniques and developments, a call for experts was opened in 2018 to gather a group of experts around the BoK. Professionals, researchers and practitioners ensure the quality of the BoK content by reviewing and providing descriptions of particular concepts with principal literature references, defining knowledge and skills, and identifying relations between them. It is expected that the collected concepts will be oriented to the current and (near-) future needs of the sector, without neglecting any important conceptual foundations relevant to a particular domain.
The EO*GI sector is constantly evolving, which is why developing and maintaining the BoK must be a continuous process. To ensure its completeness and to keep the information in the BoK up to date, the process of developing the BoK for $\mathrm{EO} * \mathrm{GI}$ is carried out with constant effort made by the existing network of experts - composed by 161 people while we are writing the paper - and by the inclusion of new ones, since there is a continuous open call for experts ${ }^{6}$ in the $\mathrm{EO}^{*} \mathrm{GI}$ sector to participate in the process of developing the EO4GEO BoK.

Since the revision strategy of the BoK is decentralised, i.e. organized individually in the WGs, different complementary ways of cooperating with experts have been put in place. Besides that, and aware of the particular complexity of contributing to crowdsourced projects, any kind of process established for contribution is welcomed as long as they are effective. Methodologies that have been used so far are: direct contribution using the LTB tool, organising virtual meetings or establishing fluent communication by email.

It is important to recognise the work done by experts. Particularly experts external to the EO4GEO project, need to be recognized as they contribute on a voluntary basis with the only aim of sharing their knowledge with the EO*GI community. So, different strategies for experts' acknowledgement are being put in place, starting with giving them visibility on the EO4GEO website $^{7}$ and the LTB tool or inviting them to co-authoring papers.

\section{FROM EO*GI CONCEPTS TO USER UPTAKE}

Knowledge exchange among users of geoinformation services presents many challenges. Development of a knowledge-driven approach is considered by the EO*GI sector to be one of the milestones for embracing its diverse group of stakeholders. The BoK is one of the means to achieve such a 'common understanding' by identifying the concepts of the domain and structuring the EO*GI services as concepts via relations, preferably with a focus on the end user from $\mathrm{EO}^{*} \mathrm{GI}$ sector. For doing so, EO4GEO recognises the experience of the European Association of Remote Sensing Companies (EARSC) in structuring the 'offer' of the sector, its products and services for the actual use of the communities for whom it is intended, the 'uptake'. Therefore, a definition of these EO*GI communities is proposed similar to the definition of concepts and can be summarized as follows:

- Managed living resources - Users in managed living resources refer to human activities exploiting natural organic resources. Knowledge and information products to forge a viable strategy for the users' operations such as the assessment of the status of the resource due to natural or human activity for effective commercial exploitation and conservation. This includes agriculture, fishing and forestry occupations for our society.

- Energy and natural resources - Users in this group deal with harvesting energy from renewable resources and extractive industries including oil, gas and raw materials. EO*GI information helps them in exploring locations for new mines or power plants, in identifying risks from infrastructure, and in managing the environmental impact of their operations. EO*GI services that apply to the extractive industries are: study of landforms, structures, and the subsurface, to understand physical processes creating and modifying the earth's crust.

- Infrastructure and transport - Users in infrastructure and transport apply to all manufacturing and physical supply in land but also marine domains including transport and logistics,

\footnotetext{
${ }^{6} \mathrm{http}: / /$ www.eo4geo.eu/eo4geo-call-for-experts/

7 http://www.eo4geo.eu/bok/
}

\footnotetext{
${ }^{3}$ https://directory.eoportal.org/web/eoportal/satellite-missions

${ }^{4} \mathrm{http://database.eohandbook.com/}$

${ }^{5}$ https://earsc-portal.eu/display/EOSTAN/EO+Wiki
} 
utilities, construction, communication and connectivity, and tourism.

- Financial and digital services - Users in this sector cover a broad area of activities that touch on many other market sectors such as insurance \& real estate, retail, news \& media and digital interfaces. The categories included are identifiable as a "service" (tertiary sector: attention, advice, access, experience, and affective labour) and are not part of the physical supply of goods. - Urban development - Users in urban development and users involved in the development of rural settlements perform tasks on local and regional scale (to the scale of nations). These users benefit from $\mathrm{EO} * \mathrm{GI}$ information to manage the use of land \& its impacts. Users such as urban planners, architects, spatial planning offices, urban policy makers in public/private sectors in smart cities or generic urban local/regional planning belong to this category.

- Defence and security - Users in defence and security work in the field of military, emergency and social protection and define, collect, and analyse information to provide knowledge and safety. Some examples are activities under humanitarian response such as border control organisations, police and rescue forces, coast guards, civil protection, military services, and intelligence services which can use EO*GI services to detect and monitor high risk areas produced naturally or by humans, monitor border incursions or maritime movements.

- Environment, climate and health - Users in the public administrations or private organizations using $\mathrm{EO}^{*} \mathrm{GI}$ to assist environmental or climate change impact policy making decisions, i.e., assisting in developing monitoring to evaluate and deliver policy goals, provide assessment of ecosystems, rapid response to major environmental risk events, or those associated with health security and care events. These users are largely related with international treaties and hence require a strong international collaboration.

- Citizens and society - Citizens and society in general use and engage with $\mathrm{EO} * \mathrm{GI}$ services through mobile devices, social media platforms, and apps. This section also contains the users in education, research and training providing learning outcomes that describe the knowledge and skills to be acquired by students in the learning process.

Further integration of the domain and community related concepts in the BoK will be established by creating relations between these uptake-oriented concepts and the technical and organisational concepts developed in the other WGs.

\section{CONCLUSIONS AND FUTURE WORK}

The EO4GEO BoK gathers the knowledge of the EO*GI domain through a rich collection of concepts and their associated skills. It will form the basis for the space/geospatial sector skills strategy by defining on the one hand academic curricula and learning paths, and describing job offers and occupational profiles on the other. In this way, it will contribute to having a workforce with the right knowledge and skills at the right time (Miguel-Lago et al., 2019).

The BoK for $\mathrm{EO} * \mathrm{GI}$ has been envisioned as an open tool to be used by the EO*GI community and also freely accessible and reusable in other domains. From the analysis of other complementary BoKs (Martirano et al., 2019), it seems this characteristic distinguishes it from complementary BoKs found in other domains, which may have restricted access (e.g., DAMA $\mathrm{BoK}$ ) or are not released in interoperable formats (e.g., GEOINT Essential BoK).

As introduced, for the update of the EO4GEO BoK a variety of informational inputs has been considered. Amongst them, the analysis of tasks extracted from BPMNs and the resulting way for creating skills were of particular interest, since they introduced a business-perspective to the BoK, not directly addressed by other BoKs in the domain (Greenfield, 2012; Moellering, 2019; Wilson, 2020). On the one hand, opening the BoK up from academia and research area to public services and industry, increases the number of BoK potential users. On the other hand, it is expected that innovative uses of the BoK will emerge.

Further exploitation of the BoK for $\mathrm{EO} * \mathrm{GI}$ can be envisioned by fully grasping the underlying ontological foundation, explained in Section 4.2.3. Through the use of standards, open and free use of and access to the BoK, and offering supporting developer tools, EO4GEO aims for full uptake and further exploitation of the potential of the BoK beyond the scope of the EO4GEO project. Within the context of the project, some of such BoKbased tools, which exploit the knowledge contained in the BoK, have been developed, e.g., Curriculum Design Tool (CDT), and Occupational Profile tool (OCT). These tools rely on the BoK's content to drive functionality, use it as a common vocabulary and to annotate different sets of information, such as academic and vocational training curricula or occupational profiles (Casteleyn, 2020). The associated tools will be described in other papers and publications. By providing a common vocabulary the BoK serves as a hub interconnecting all these different tools and data sources. In a next step an online platform can be created where the BoK is the entry point to get access to all these resources.

Given the rapid advancement of the sector, future work regarding the BoK for EO*GI has to do with the setup of a sustained network of experts for updating the BoK on a continuous basis. Additionally, the existence of other BoKs (Greenfield, 2012; Moellering, 2019; Wilson, 2020) puts the high dynamism of the EO*GI sector and its community into context. From the EO4GEO project it is the ambition to look for synergies with complementary BoKs, not just in the $\mathrm{EO} * \mathrm{GI}$ domain, but in other domains closely related (e.g., Computer Science). These synergies could also unleash the untapped potential of the BoK for $\mathrm{EO} * \mathrm{GI}$. Further uses, like the analysis of trends on $\mathrm{EO} * \mathrm{GI}$ by annotating the proceedings of main conferences in the sector, or the description of EO*GI experts profiles based on the BoK, could also help for a better understanding of the evolution of the sector and its workforce.

\section{ACKNOWLEDGEMENTS}

The EO4GEO project would like to thank the scientists and specialists from the $\mathrm{EO} * \mathrm{GI}$ sector who have already registered as EO4GEO experts willing to support the development of EO4GEO BoK and ensure the completeness and highest professional standards of its content.

The EO4GEO project would like to thank the Education, Audiovisual and Culture Executive Agency (EACEA).

The project is co-funded by the Erasmus+ Programme of the European Union Sector Skills Alliances N 591991-EPP-1-20171-IT-EPPKA2-SSA-B.

\section{REFERENCES}

Ahearn, S., Icke, I., Data, R., DeMers, M.N., Plewe, B., Skupin, A., 2013. Re-engineering the GIS\&T Body of Knowledge. International Journal of Geographical Information Science, 27 (11) 2227-2245. doi.org/10.1080/13658816.2013.802324.

Anderson, L. W., Krathwohl, D. R. 2001. A Taxonomy for Learning, Teaching and Assessing: A Revision of Bloom's Taxonomy of Educational Objectives. New York: Longman. 
Bloom, B. (ed.) et.al. 1956. Taxonomy of Educational Objectives. The Classification of Educational Goals: Handbook 1 Cognitive Domain. Longmans, New York,

Brooks, T., Kantor, C. , Spuria, L., Quinn, K. (Eds.), 2019. The Geospatial Intelligence Essential Body of Knowledge, Version 2.0/2019, Compiled by the United States Geospatial Intelligence Foundation.

https://usgif.org/system/uploads/6127/original/EBK.pdf (3 May 2020)

Casteleyn, S., 2020. EO4GEO ecosystem of tools for educators and practitioners. Medium

https://medium.com/@EO4GEO/eo4geo-ecosystem-of-tools-

for-educators-and-practitioners-c3055f669a8 (1 May 2020)

Cipriano, P., Easton, C., Roglia, E., Vancauwenberghe, G., 2013. A European Community of SMEs built on Environmental Digital Content and Languages. SME Inspire project Final Report. http://www.smespire.eu/wpcontent/uploads/downloads/2014/09/D1.3_FinalReport_1.0.pdf (28 April 2020)

DAMA International, 2017. DAMA-DMBOK: Data Management Body of Knowledge. 2nd Edition. Technics Publications

Delponte, C., Pellegrin, J., Sirtori, E., Gianinetto, M., Boschetti, L., 2016 Space market uptake in Europe. Directorate General For Internal Policies Policy Department A: Economic And Scientific Policy, IP/A/ITRE/2015-03 PE 569.984. https://www.europarl.europa.eu/RegData/etudes/STUD/2016/56 9984/IPOL_STU\%282016\%29569984_EN.pdf (25 April 2020)

DiBiase, D., DeMers, M., Johnson, A., Kemp, K., Luck, A. T., Plewe, B., Wentz, E., 2006. Geographic Information Science and Technology Body of Knowledge. Association of American Geographers and University Consortium for Geographic Information Science. Washington http://downloads2.esri.com/edcomm2007/bok/GISandT_Body_ of_knowledge.pdf (1 May 2020)

Dupuis, R., Bourque, P., Abran, A., 2003. SWEBOK Guide An overview of trial usages in the field of education, 33rd ASEE/IEEE Frontiers in Education Conference, November 5-8, 2003, Boulder, CO.

EARSC, 2015. Taxonomy for EO services. http://earsc.org/file_download/489/A+Taxonomy+for+the+EO+ Services+Market+issue+2+\%282\%29.pdf (20 April 2020)

EU, 2017. Official Journal of the European Union. Council Recommendation of 22 May 2017 on the European Qualifications Framework for lifelong learning and repealing the Recommendation of the European Parliament and of the Council of 23 of April of 2008 on the establishment of the European Qualifications Framework for lifelong learning. https://ec.europa.eu/ploteus/sites/eac-eqf/files/en.pdf (1 May 2020)

Fairbairn, D., 2017. Creating a Body of Knowledge for Cartography. Proceedings of the International Cartographic Association, 1, 2017. doi.org/10.5194/ica-proc-1-35-2017

Greenfeld, J., 2012. Surveying body of knowledge. Surveying and Land Information Science. 71. 105-113.

Gruijthuijsen, W., Pontes, S., Vancauwenberghe, G., Vandenbroucke, D., Olijslagers, M., 2019. Understanding skill needs in the EO/GI sector: a job advertisements analysis. In: Kyriakidis, P., Hadjimitsis, D., Skarlatos, D. \& Mansourian, A. (Eds.), 2019. Accepted Short Papers and Posters from the 22nd AGILE Conference on Geo-information Science. Cyprus University of Technology 17-20 June 2019, Limassol, Cyprus. Stichting AGILE.

https://agile-

online.org/images/conference_2019/documents/short_papers/95 _Upload_your_PDF_file.pdf (1 May 2020)

Hofer, B., d'Oleire Oltmanns, S., Ferber, N., Albrecht, F., Lang, S., 2019. Demand for space/geospatial education and training and priority occupational profiles. Report of the EO4GEO Project funded with the support of the Erasmus+ Programme of the European Union Sector Skills Alliances N 591991-EPP-1-20171-IT-EPPKA2-SSA-B. Available

http://www.eo4geo.eu/download/eo4geo_d1-

3_demand_for_space-

geospatial_education_and_training_and_priority_occupational_ profiles_v2-1/?wpdmdl=3840\&masterkey=5cfe849bd1fee $\quad(15$ April 2020)

Hofer, B., Lang, S., Ferber, N., 2020a. Future Occupational Profiles in Earth Observation and Geoinformation - Scenarios Resulting from Changing Workflows. In: Kyriakidis P., Hadjimitsis D., Skarlatos D., Mansourian A. (eds) Geospatial Technologies for Local and Regional Development. AGILE 2019. Lecture Notes in Geoinformation and Cartography. Springer, Cham. doi.org/10.1007/978-3-030-14745-7_19.

Hofer, B., Casteleyn, S., Missoni-Steinbacher, E.M., AguilarMoreno, E., Albrecht, F., Lemmens, R., Lang, S., Albrecht, J., Stelmaszczuk-Górska, M.A., Vancauwenberghe, G., MonfortMuriach, A., 2020b: From Tasks to Concepts and Skills Complementing the Body of Knowledge with a Businessoriented Perspective. Transactions in GIS. (accepted)

Kemp, K.K. and M.F. Goodchild. 1991. Developing a curriculum in Geographic Information Systems. The National Center for Geographic Information and Analysis Core Curriculum project. Journal of Geography in Higher Education, 15(2):121-132.

Lemmens, R. L. G., Ronzhin, S., Augustijn, P. W. M., Verkroost, M. J., Walsh, N., 2018. Space Education with The Living Textbook, A web-based tool using a Concept Browser. Paper presented at 2nd Symposium on Space Educational Activities, SSEA 2018, Budapest, Hungary.

Martirano, G., Bilotti, L., Vercillo, A., 2019. Linking the BoK for GI and EO to other BoKs. Report of the EO4GEO Project funded with the support of the Erasmus+ Programme of the European Union Sector Skills Alliances $N^{\circ}$ 591991-EPP-1-2017-1-ITEPPKA2-SSA-B. Retrieved from: http://www.eo4geo.eu/download/eo4geo_d2-4-linking-the-bokfor-gi-and-eo-to-other-boks_v2-

1/?wpdmdl=4543\&masterkey=5dc176f43b645 (3 May 2020))

Miguel-Lago, M. et al., 2019. Space/Geospatial Sector Skills Strategy. Report of the EO4GEO Project funded with the support of the Erasmus+ Programme of the European Union Sector Skills Alliances N 591991-EPP-1-2017-1-IT-EPPKA2-SSA-B. http://www.eo4geo.eu/download/d-1-6-spacegeospatial_sector_skills_strategy_v20/?wpdmdl=3800\&masterkey=5ce6e2483a83c (3 May 2020)

Moellering, H., 2019. Analytical Background for Developing a Body of Knowledge for Cartography, Proc. Int. Cartogr. Assoc., 2, 87, https://doi.org/10.5194/ica-proc-2-87-2019, 2019. 
Mouratidis, A., Koutsoukos, M., 2016. Use of ESA Earth Observation Educational Resources in Vocational Education and Training - Lifelong Learning: Towards STEM promotion and development of skills. Bulletin of the Geological Society of Greece,50(3), 1652-1661, doi.org/10.12681/bgsg.11888.

PMI, 2017. A Guide to the Project Management Body of Knowledge: PMBOK ${ }^{\circledR}$ Guide. 6th edition. Project Management Institute.

Rickles, P., Ellul, C., Haklay, M., 2017. A Suggested Framework and Guidelines for Learning GIS in Interdisciplinary Research. Geo: Geography and Environment, 4(2), 1-18. doi.org/10.1002/geo2.46.

Rip, F., Wallentin, G., van Lammeren, R, 2014. Integrated analysis of the demand for and supply of geospatial education and training. Report of the GI-N2K - Geographic Information Need to Know Project LLP - Erasmus Academic Network N ${ }^{\circ}$ 540409-LLP-1-2013-1-BEERASMUS-ENW. http://www.gin2k.eu/?wpdmdl=452 (3 May 2020)

Rosing, M. Von, Scheel, H. von, Scheer, August-Wilhelm., 2015. The Complete Business Process Handbook, Volume 1 - Body of Knowledge from Process Modeling to BPM. Elsevier - Morgan Kaufmann. p. 776, ISBN 978-0-12-799959-3.

PwC, 2019. Copernicus - Market Report. Report for the European Commission. Issue 2.

https://www.copernicus.eu/sites/default/files/2019-

02/PwC_Copernicus_Market_Report_2019_PDF_version.pdf (1 May 2020)

Sudmanns, M., Tiede, D., Lang, S., Bergstedt, H., Trost, G., Augustin, H., Baraldi, A., Blaschke, T., 2019. Big Earth data: disruptive changes in Earth observation data management and analysis? International Journal of Digital Earth, 1-19. doi.org/10.1080/17538947.2019.1585976.

Vandenbroucke, D., Gruijthuijsen, W., Olijslagers, M. Vancauwenberghe, G., Monfort Muriach, A., Casteleyn, S., Aguilar, E., Rob Lemmens, R., Stelmaszczuk-Górska, M., 2019. D2.2 - Revised ontology-based approach. Report of the EO4GEO Project funded with the support of the Erasmus+ Programme of the European Union Sector Skills Alliances N 591991-EPP-12017-1-IT-EPPKA2-SSA-B.

http://www.eo4geo.eu/download/eo4geo_d-2-2-revisedontology-based-approach_v2-

0/?wpdmdl=3491\&masterkey=5c5b01d87d8bd (1 May 2020)

Vandenbroucke, D., Vancauwenberghe, G., 2016. Towards a New Body of Knowledge for Geographic Information Science and Technology. Micro, Macro \& Mezzo Geoinformation, 2016 (6), 7-19.

Vlad Sandru, M. I., Nedelcu, I., Hofer, B., Missoni-Steinbacher, E. M., 2020. Business processes and occupational profiles. Report of the EO4GEO Project funded with the support of the Erasmus+ Programme of the European Union Sector Skills Alliances $\quad \mathrm{N}^{\circ}$ 591991-EPP-1-2017-1-IT-EPPKA2-SSA-B. Available at http://www.eo4geo.eu/download/d4-1_business-processes-andoccupational-profiles_v2-

0/?wpdmdl=4827\&masterkey=5e45a07016892 (2 May 2020)
Wilson, J.P. (ed.) 2020. The Geographic Information Science \& Technology Body of Knowledge (1st Quarter 2020 Edition). https://gistbok.ucgis.org/ (30 April 2020) 